\title{
Climate mode simulation of North Atlantic polar lows in a limited area model
}

\author{
By MATTHIAS ZAHN ${ }^{1,2 *}$, HANS VON STORCH ${ }^{1,2}$ and STEPHAN BAKAN ${ }^{3},{ }^{1}$ Institute for Coastal \\ Research GKSS Research Center, System Analysis and Modelling, Max-Planck-Straße 1, D-21502 Geesthacht, \\ Germany; ${ }^{2}$ Meteorological Institute of the University of Hamburg, Bundesstr. 55, D-20146 Hamburg, Germany; \\ ${ }^{3}$ Max Planck Institute for Meteorology, Bundesstr. 53, D-20146 Hamburg, Germany
}

(Manuscript received 18 June 2007; in final form 10 March 2008)

\begin{abstract}
Polar lows are not properly resolved in global re-analyses. In order to describe the year-to-year variability and decadal trends in the formation of such mesoscale storms, atmospheric limited area models, which post-process re-analysis data, may be an appropriate tool. In this study we demonstrate the merits and potential of this approach.

A series of 3-week long ensemble simulations of weather situations over the NE Atlantic with a limited area model/regional climate model (CLM) are examined. The model was driven with NCEP-NCAR re-analyses at the lateral and lower boundaries. Additionally, the spectral nudging technique was used to enforce the large-scale circulation, as given by the NCEP-NCAR reanalysis, on the simulation. The ensemble members differ by initial conditions taken from several consecutive days.

In most of the cases, a polar low developed after a simulated time of about 2 weeks, that is, long after the initialization of the model calculations.

The spectrally nudged version of the model is very insensitive to initial conditions. The observed polar lows were reproduced in all ensemble members. A reasonable correlation between the simulated polar low features and those derived from a satellite product (HOAPS-III) and operational high-resolution weather analyses (DWD) is found. The polar lows are considerably deepened compared to the driving NCEP-NCAR analysis, but the comparison with weather maps indicates some differences in detail.

When CLM is run without the large-scale constraint of spectral nudging, considerable variability emerges across the different ensemble members and the observed polar low often does not emerge.
\end{abstract}

\section{Introduction}

The term polar low is used for a spectrum of different intense maritime small and mesoscale (horizontal diameter up to 1000 $\mathrm{km}$ ) cyclones forming poleward the Polar Front in both hemispheres (Rasmussen and Turner, 2003). Because they are associated with surface wind speeds near or above gale force, severe weather and heavy precipitation, they constitute a significant part of the marine weather risk in subpolar waters.

A variety of initial conditions and forcing mechanisms, which usually interact with each other, are thought of as being responsible for polar low development. Early studies focused on baroclinic environments as an initial condition for polar low development (e.g. Harrold and Browning, 1969) as well as approaching upper level disturbances (Harrold and Browning,

\footnotetext{
* Corresponding author.

e-mail: matthias.zahn@gkss.de

DOI: $10.1111 / \mathrm{j} .1600-0870.2008 .00330 . x$
}

1969; Rasmussen, 1985). To explain their further development conditional instability of the second kind (e.g. Rasmussen, 1979) and air sea interaction instability (Emanuel, 1986; Emanuel and Rotunno, 1989), subsequently renamed Wind Induced Surface Heat Exchange, are considered as being important for polar low development.

More recently a wealth of sensitivity and diagnostic studies of polar low occurrences in the North Atlantic applying high resolution numerical models were undertaken to increase the understanding of the dynamical processes involved (Nordeng and Rasmussen, 1991; Grønås and Kvamstø, 1995; Mailhot et al., 1996; Nielsen, 1997; Claud et al., 2004). Further numerical studies were undertaken for other parts in the Northern Hemisphere by Yanase et al. $(2002,2004)$ for the Japan Sea, Blier (1996) and Bresch et al. (1997) for the Gulf of Alaska and Lee et al. (1998) for the Korean Peninsula as well as for the Antarctic (Heinemann, 1998; Heinemann and Klein, 2003). All of them succeed in reproducing the respective polar low case reasonably. 
In addition to these process studies, studies focusing on climatological aspects of mesocyclones and polar lows were conducted in the northern (Wilhelmsen, 1985; Harold et al., 1999a,b) as well as in the southern hemisphere (e.g. Carleton and Carpenter, 1990). As these studies were primarily based on satellite imagery or observations, they only describe a limited time period and also suffer from a lack of homogeneity. Further uncertainties emerge from the subjective way of detection. A first objective climatology of polar lows was compiled by Bracegirdle and Gray (2008) based on applying objective criteria for the identification of polar lows to numerical weather prediction data. However these data were available for a relatively short time period only.

The construction of comprehensive multidecadal climatological statistics of polar low occurrences has not been achieved so far. However, such knowledge is needed to assess interannual variability and decadal trends, and for evaluating possible connections or contributions to larger scale climatic changes in the past and future. Presently available long-term databases, that possibly enable an assessment of such questions, usually suffer from inhomogeneities, that is, changes over time are related to changing analysis tools and skills. However, data homogeneity is a key requisite for robust assessments of ongoing change.

We have begun to implement a technique which we hope will allow us to overcome the limitation of too short and inhomogeneous data. The basic idea is to run an atmospheric limited area model covering the NE Atlantic with global re-analyses at the lateral and lower boundaries. Additionally a large-scale constraint applied in the interior to impose the reliably and homogeneously analysed large-scale atmospheric state on the mesoscale formation and life cycle of polar lows. Recently, such re-analysis data was used by Kolstad (2006) to detect 'reverse shear flow' atmospheric conditions, which favour the development of a particular kind of polar low. Also using the relatively coarsely gridded reanalysis data, Condron et al. (2006) investigated climatological aspects of mesocyclones by locating the maxima in the Laplacian of the pressure field or geopotential height.

In this paper, we want to investigate whether a higher resolution atmospheric limited area model (LAM)/regional climate model (RCM), as used in long term retrospective reconstructions of the detailed weather stream (e.g. Weisse et al., 2005), is capable of reproducing such subpolar maritime mesoscale features. In doing so, we implicitly assume the validity of the 'downscaling concept', namely that the interaction of a given large-scale flow with the regional physiographic details will cause the formation of mesoscale features.

The above mentioned sensitivity or diagnostic studies are conducted in order to accurately simulate the dynamical processes involved in polar low development. Therefore, the best possible large-scale fields are used as initial fields, which usually are close to the times of the respective polar low occurrences. Contrary to those studies we want to investigate if and how well polar lows can be reproduced in climate mode simulations, which are ini- tialized long before their formation. The formation takes place approximately 2 weeks after initialization and thus is not directly dependent on the initial state, but depends on the constraints placed on the model at its boundaries and on its large-scale state.

In this study we present results from a feasibility study, as to whether our dynamical downscaling set-up of an atmospheric limited area model run in climate mode is indeed generating the additional mesoscale information. Therefore, on the one hand we drive the model in the conventional way forced at the margins and on the second hand we additionally make use of the spectral nuding technique (von Storch et al., 2000) to enforce a given large-scale onto the simulations. We examine in a series of three independent case studies, if and how good polar lows are reproduced in such a set-up. Therefore, 3-week long ensemblesimulations with a LAM/RCM were undertaken for three polar low occurrences and compared to observational data.

In Section 2, we describe the used LAM/RCM, its setup and the observational data, in Section 3 we describe the general results for the first case in Section 3.1 and for the mesoscale in Section 3.2. In Section 3.3, the results for the two other cases are shown. We end with a summary and conclusion in Section 4.

\section{Regional model and simulations}

The LAM/RCM applied in the present study is the atmospheric limited area model CLM (http://clm-community.eu) (Böhm et al., 2006). CLM is the climate version of the 'Lokal Model' LM (Steppeler et al., 2003) of the German Weather Service. Its prognostic, non-hydrostatic equations feature the variables horizontal and vertical wind, real temperature, pressure, specific humidity and specific cloud liquid water content on a hybrid coordinate system with $32 \sigma$-levels. Initial and lateral boundary values are provided by the NCEP-NCAR re-analyses (Kalnay et al., 1996). The latter are available every $6 \mathrm{~h}$ with a grid resolution of $2^{\circ}(\sim 220 \mathrm{~km})$ and are nudged in a lateral 'sponge zone' towards the NCEP-NCAR re-analyses (Davies, 1976). CLM has been used for a number of climatological investigations (e.g. Böhm et al., 2004; Déqué et al., 2005; Woth et al., 2006) but so far not for investigations in polar regions.

Our simulations are run on a rotated grid with $0.44^{\circ}$ grid resolution and a longitudinal and latitudinal grid of 184 and 72 points, respectively, with an integration time step of 240 seconds. The north pole of our rotated geographical grid is located at $175^{\circ} \mathrm{E}$ and $21.3^{\circ} \mathrm{N}$. The simulation area is a rectangle with side lengths of $8987 \times 3516 \mathrm{~km}$ (Fig. 1). Regions prone to shallow baroclinic zones along the ice edge where polar lows often form are included in the model area.

We examine a sample of three cases of polar low formation in the Northeast Atlantic, one in January 1998, and two in 1993, October and December. In these cases reasonable observational data is available. The cases have been randomly picked from a set of cases described in Rasmussen and Turner (2003). For each polar low case an ensemble of four simulations of 3 weeks in 


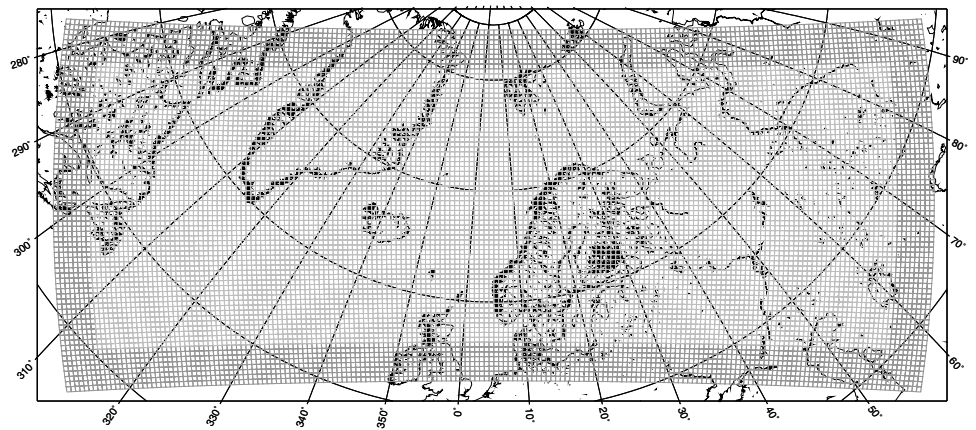

Fig. 1. Model grid used for this study. Darker grid boxes at the border represent the sponge zone.

length was performed. All simulations are begun about 2 weeks prior to the formation of the polar low, so that the dynamical development should be independent of the details of the initialization. The members of the respective ensembles differ by their initial date. They are separated by $24 \mathrm{~h}$ in order to create different, but consistent, initial states.

One ensemble was performed with constraining CLM only at the lateral boundaries and by the SST and sea ice conditions; these simulations are named 'non-nudged' (CLM-nn). A second set of ensembles additionally makes use of spectral nudging (von Storch et al., 2000), referred to as CLM-sn. Spectral nudging is a mathematical method used to enforce a given large-scale field in the simulation of the LAM. Experiments (Feser, 2006) have demonstrated that, while the large-scale circulations are efficiently constrained, the mesoscale variability conditioned by the given large-scale state is not significantly limited by this procedure. The key parameter for spectral nudging is the spectral range, within which the constraint is acting. Here we have chosen zonal wave numbers up to 14 relative to $8987 \mathrm{~km}$ and meridional wave numbers up to 5 relative to $3516 \mathrm{~km}$ as being constraint (corresponding to a spatial scale of approximately $700 \mathrm{~km}$ and more). The constraint is implemented with a vertically growing strength ( $\alpha=0.5$; von Storch et al., 2000) at $850 \mathrm{hPa}$ and above.

To assess the realism of the simulation data we compared it with a number of observation based data sources. First, the manually drawn mean sea level pressure maps from Berliner Wetterkarte and from the German Meteorological Service (DWD) are applied. Also originating from the DWD a second data set comprises the operational regional analyses available from 1993 until 1998 with a grid resolution of $0.5^{\circ}$.

A third data set contains almost instantaneous wind speeds from satellite soundings in the Hamburg Ocean Atmosphere Parameters and Fluxes from Satellite Data set (HOAPS, Andersson et al. (2007); www.hoaps.org). For the present study the HOAPS data were available between 1988 and 2002 on a regular grid of $0.5^{\circ}$ for individual satellite overpasses. The applied wind algorithm uses a neural network to infer wind speed at $10 \mathrm{~m}$ height above the sea surface from Special Sensor Microwave/Imager (SSM/I) measurements. It consists of an input layer for the brightness temperatures of 5 microwave channels, a hidden layer with three neurons and an output layer containing the wind speed. The network was trained with a composite data set from buoy measurements and radiative transfer simulations. The accuracy of these wind speed data is estimated at about $1.5 \mathrm{~m} \mathrm{~s}^{-1}$ from theoretical considerations and observational comparison studies. In contrast to the first two data products, the HOAPS wind fields are not available at synoptic dates but instantaneously during satellite overpasses and they are generally only partially filled along satellite swaths.

\section{Results}

In this section, first the model's general ability to describe one polar low case including its track is presented and the large-scale circulation in the analyses and model simulations are compared. Secondly, details of this polar low formation are considered. This is done by filtering out large-scale components, so that only mesoscale features enter the analysis. Finally, results for two other cases are discussed.

\subsection{Comparison of simulations with analyses and observations}

The mentioned first case is the October 1993 polar low as described by Nielsen (1997), Claud et al. (2004) and Bracegirdle and Gray (2006). Hereafter this particular case is referred to as 'Le Cygne' (the swan) according to the naming in Claud et al. (2004). 'Le Cygne' started to develop on 14 October mainly due to baroclinic instability and also, but of less importance, in connection with upper level vorticity advection. The proximity of a synoptic extra-tropical cyclone north of Scandinavia induced a cold air outbreak. Thus strong sea surface-air temperature differences gave rise to air sea interaction processes, latent heat fluxes and conversion into kinetic energy intensifying 'Le Cygne'. 'Le Cygne' moved equator ward approximately parallel to the Norwegian coast and eventually decayed after making landfall in Southern Norway on 16 October. An AVHRR image from the NOAA 11 satellite (Fig. 2a) shows the spiral cloud pattern of this polar low in its mature phase off the Norwegian coast centred at approximately $64^{\circ} \mathrm{N}, 1^{\circ} \mathrm{W}$ at 1329 UTC 15 October 1993. The synoptic situation is described by the Berliner Wetterkarte 

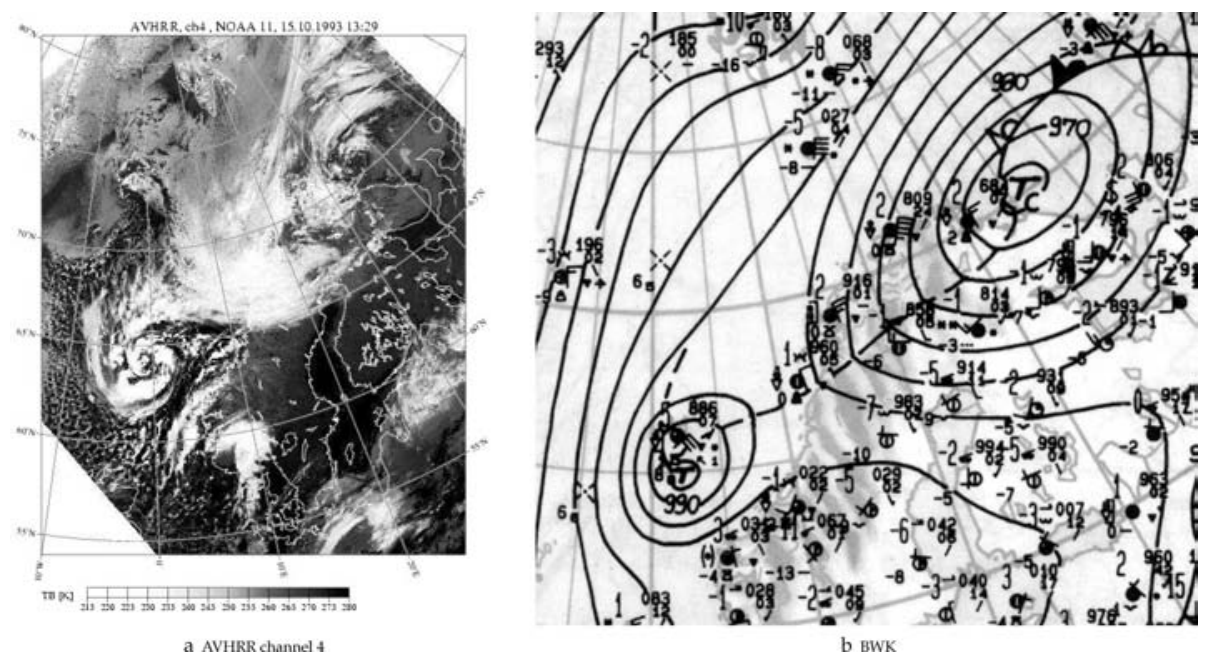

Fig. 2. (a) AVHRR NOAA 11 satellite image at 1329 UTC 15 July 1993 (adapted from Claud et al., 2004), and (b) surface weather chart from the Free University of Berlin at 0700 UTC 15 October 1993 (Berliner Wetterkarte 1993).

in Fig. 2b, with a synoptic low pressure system at the northern tip of Scandinavia and the small polar low at about $65^{\circ} \mathrm{N}, 2^{\circ} \mathrm{E}$.

For this case two ensembles of four nudged and four nonnudged simulations were started at 0000 UTC on 1, 2, 3 and 4 October 1993, respectively. These simulations are named referring to the day of initialisation, namely CLM01-sn, CLM02-sn, CLM03-sn and CLM04-sn for the nudged ones and CLM01nn, CLM02-nn, CLM03-nn and CLM04-nn for the non-nudged runs.

Synoptic conditions of the analyses at the time when 'Le Cygne' is in its mature state (Figs. 3a and b) coincide with the description in Fig. 2 in terms of air pressure and surface wind. In the analysis of the German Weather Service DWD, a mesoscale pressure minimum at approximately $65^{\circ} \mathrm{N}, 1^{\circ} \mathrm{E}$ represents the polar low at the south western margin of the synoptic low centred further to the northeast. The NCEP-NCAR map is much smoother, with the polar low reduced to a minor low pressure trough.

The simulated CLM-sn sea level pressure fields at the time of this polar low occurrence are shown in Figs. 3c-f. All four maps are rather similar, demonstrating the efficient control exerted by the spectral nudging. For the simulated synoptic lows the core pressure below $970 \mathrm{hPa}$ and the location at the northern tip of Scandinavia are in very good accordance with the observations. Also the polar low is shown as closed isobars around the pressure minima indicated by the black dot in all of the ensemble members. Near-gale $10 \mathrm{~m}$ wind speeds of $13.9 \mathrm{~m} \mathrm{~s}^{-1}$ and more at its western side justify the usage of the term 'polar low' after the definition used by Rasmussen and Turner (2003). However, the polar low core pressures do not decrease below $1000 \mathrm{hPa}$. This is different in the pressure field from the DWD, where the minimum core pressure falls below $990 \mathrm{hPa}$, and to 'Berliner Wetterkarte', where sea level pressure even drops below $985 \mathrm{~Pa}$. In the forecast simulations undertaken by Nielsen (1997) this pressure minimum is somewhat higher, namely above $990 \mathrm{hPa}$ and above $992 \mathrm{hPa}$ in Claud et al. (2004). We state that CLM produces a polar low like feature, but its pressure minimum is at least $10 \mathrm{hPa}$ too high compared to other data. Additionally our simulations deviate from the observations by a too late development and a location too far north.

The exact reason for this misplacement cannot be determined, but we assume that it could be due to the processes initiating the development of 'Le Cygne'. Following Nielsen (1997) the polar low most likely is induced in the lower atmosphere in a shallow baroclinic environment, which established in a northerly flow caused by the adjacent synoptic low. These lower levels are not directly affected by our nudging procedure operating in levels above $850 \mathrm{hPa}$. Therefore, we argue that the baroclinicity causing the disturbance probably is reproduced, but the exact position and time, where and when the polar low emerges within this environment is random. The position of the upper level disturbance does not determine the development alone in this case.

In the four CLM-nn-runs without large-scale constraint (Fig. 3j) the observed synoptic scale (large-scale) low develops too. But these large-scale features strongly differ from the features described by NCEP-NCAR. Also, the evolving maps differ substantially among each other. In CLM02-nn and CLM03-nn, the positions of the synoptic lows agree, but the curvatures of the inner isobars differ. In CLM01-nn and CLM04-nn the locations of the synoptic lows are shifted and the extended oval shapes of the synoptic lows have no counterpart in the NCEPNCAR reanalysis. Only in CLM02-nn and CLM03-nn, a polar low forms appearing in substantially different ways. In CLM01nn and CLM04-nn pressure troughs, but no polar low-like features emerge.

Similar to the nudged simulations, favourable conditions for polar low development with a northerly wind flow also prevail in the non-nudged simulations. In the ensemble members, which 

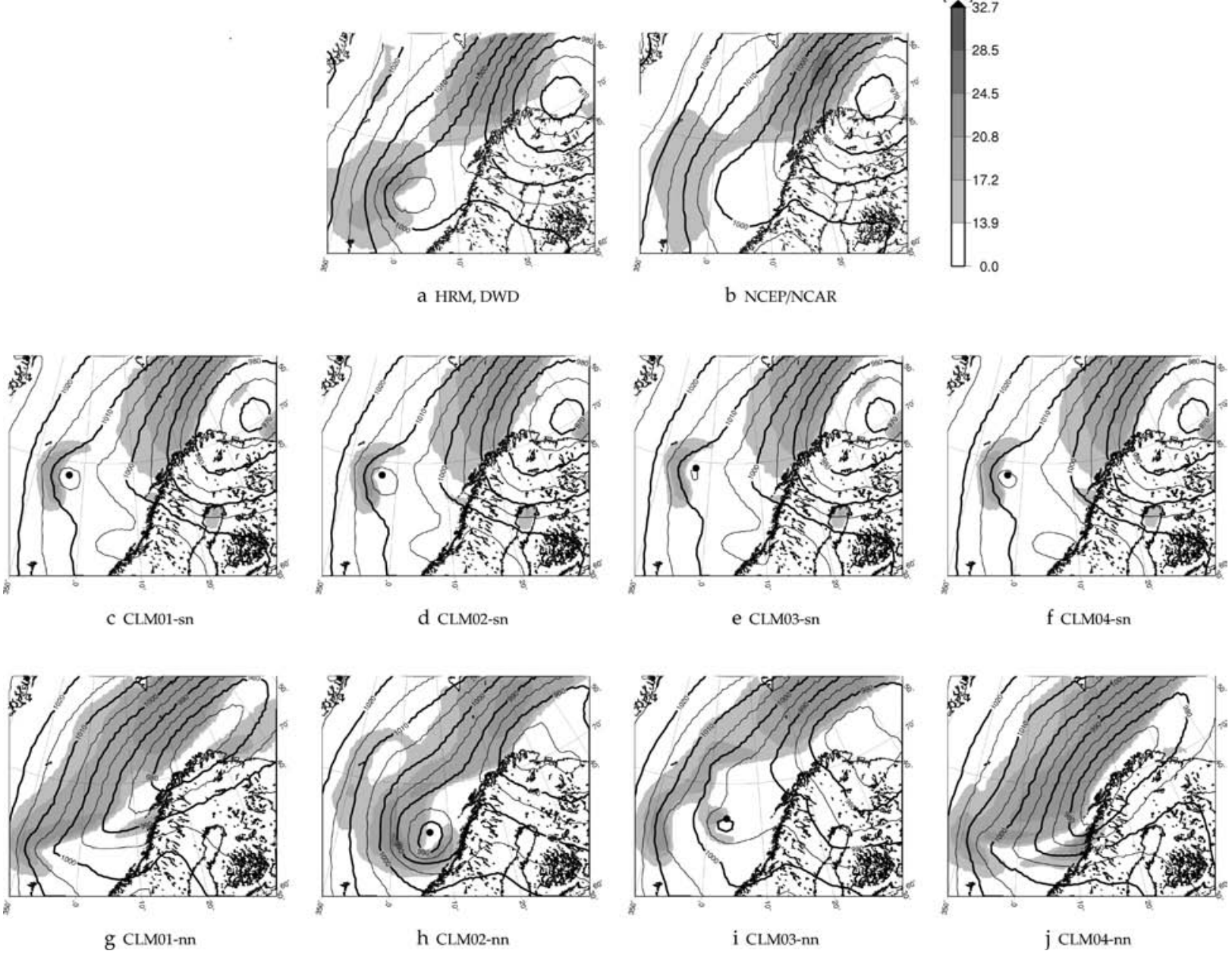

Fig. 3. $10 \mathrm{~m}$ wind speed $\geq 13.9 \mathrm{~m} \mathrm{~s}^{-1}$ and air pressure (at mean sea level) at 0600 UTC 15 October 1993: (a) DWD analysis data, (b) NCEP-NCAR analysis after interpolation onto the CLM grid, 0600 UTC, (c-f) CLM ensemble run with spectral nudging and (g-j) without, 0900 UTC,

initialization times of the simulations are 1-4 October, respectively. If existent, black dots indicate the positions of the polar low's pressure minimum in the respective run.

do not reproduce the polar low, the synoptic low is located farther west. Thus the synoptic low's back circulation, the area in which the polar low develops, is shifted farther west into regions less affected by the warm water supply of the gulf stream. We suggest that lower surface temperatures, and thus a smaller air-sea temperature difference, inhibit the transformation of a mesoscale development into the polar low.

We developed a simple algorithm to track the local surface pressure minima. Based on manually provided coordinates at 1500 UTC 14 October 1993, when the polar low emerged, this algorithm finds the nearest local minimum in the next time step $(3 \mathrm{~h})$ of the output data and so on. The resulting sequences of positions for CLM-sn are illustrated in Fig. 4 and can be interpreted as tracks of the simulated polar low. In all four cases, these tracks are very similar. Following a north-south direction, they are in accordance with the track described in Nielsen (1997).
In CLM01-nn and CLM04-nn a track could not be identified because clear pressure minima were lacking. The polar low-like features in CLM02-nn and CLM03-nn developed very close to the Norwegian coast, remained there and made landfall near Trondheim leading to wrong tracks (not shown).

We compared the instantaneous satellite-derived wind speed estimates (HOAPS) with the simulated fields; only CLM01-sn is considered (Fig. 5a) - the other three sn-cases are virtually identical. For the 'nn' ensemble we show two cases, namely CLM01-nn without the formation of a polar low (Fig. 5b) and CLM02-nn with such a formation (Fig. 5c). We think that these instantaneous wind speeds are suitable for representing the wind field pattern.

This comparison also reveals the advantage of the nudged simulations. Differences generated between HOAPS and CLM01sn show the smoothest pattern. Apart from higher CLM wind speed off the coast of Southern Norway, differences larger than 

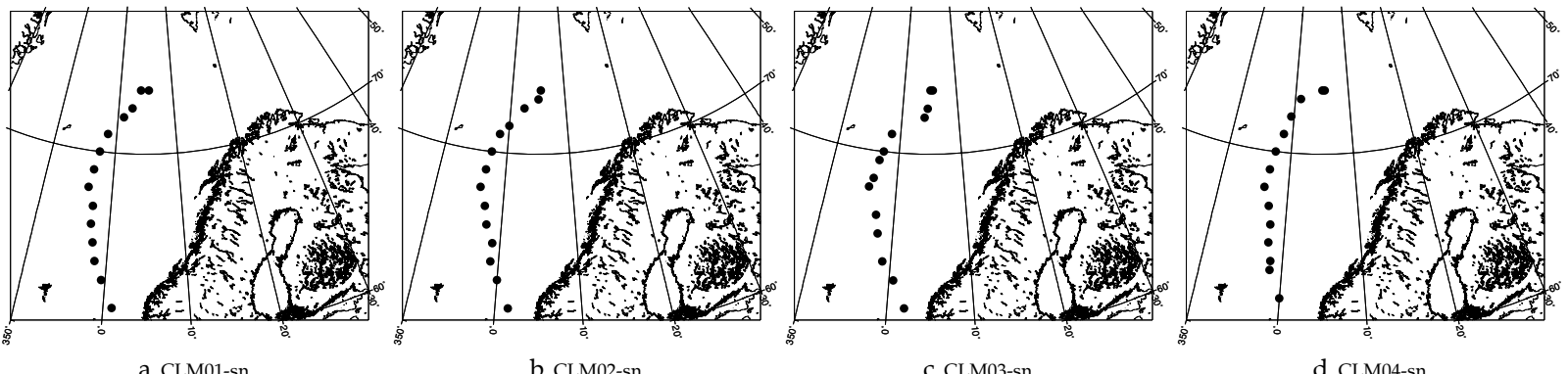

Fig. 4. Sequences of positions of the polar low-like local pressure minima for CLM01-sn, CLM02-sn, CLM03-sn and CLM04-sn from 1500 UTC 14 October until 0600 UTC 16 October 1993. The time interval is $3 \mathrm{~h}$, respectively.
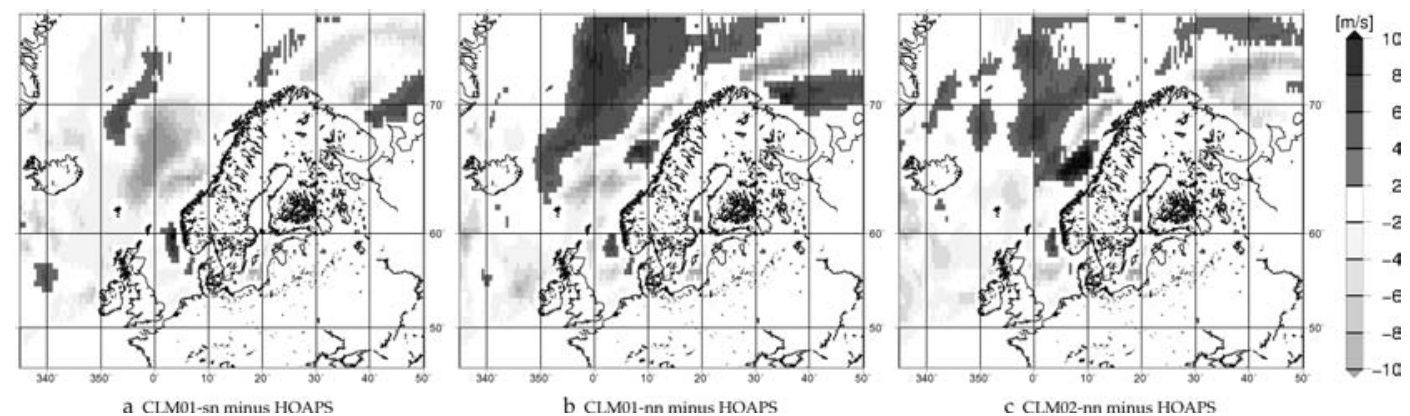

Fig. 5. Difference maps for $10 \mathrm{~m}$ wind speed as provided by CLM with spectral nudging (CLM01-sn) and without spectral nudging (CLM01-nn and CLM02-nn) compared to HOAPS-estimates on 15 October 1993, 0-12 UTC.

approximately $8 \mathrm{~m} \mathrm{~s}^{-1}$ occur over most of the polar low's area. However, for the whole field a mean difference of $-1.92 \mathrm{~m} \mathrm{~s}^{-1}$ was calculated. Such a mean difference is larger than the overall mean difference of $-1.16 \mathrm{~m} \mathrm{~s}^{-1}$ calculated from 1 to 20 October. Remarkably higher wind speeds in HOAPS in the polar low's area contribute to this discrepancy, whereas CLM01-sn produced higher wind speeds farther north-west, reflecting the somewhat shifted position of the polar low in CLM01-sn. The spatial standard deviation amounts to $3.27 \mathrm{~m} \mathrm{~s}^{-1}$, which is almost one and a half as large as the spatial standard deviation of the difference field between HOAPS and DWD of $2.28 \mathrm{~m} \mathrm{~s}^{-1}$.

The differences between HOAPS and CLM-nn exceed $8 \mathrm{~m} \mathrm{~s}^{-1}$ in many parts of the area. The oval shaped synoptic low of CLM01-nn, which is not seen in observations, was discussed above. This low produces a large-scale high wind speed field to its western side leading to large positive differences with HOAPS (Fig. 5b). Contrary to CLM01-sn this leads to a notably smaller mean difference of $0.02 \mathrm{~m} \mathrm{~s}^{-1}$ between the two fields of CLM01-nn and HOAPS. Though a higher standard deviation of $4.02 \mathrm{~m} \mathrm{~s}^{-1}$ indicates locally higher differences. For the CLM02-nn case a simulated polar low with a spatially somewhat larger extension delivers values in between, namely $-0.44 \pm 3.51 \mathrm{~m} \mathrm{~s}^{-1}$.

\subsection{Scale separation}

In this subsection, we expand the findings of the previous subsection by focusing on the mesoscale features of the output fields.
Thereby we want to highlight a technique that might be helpful for the automated detection of mesoscale disturbances by making them more distinct.

The retrospective simulation is based on the assumption that the limited area model provides additional detail on mesoscales over the driving NCEP-NCAR re-analysis. Whether this expectation is valid is examined by comparing the performance of the retrospective simulation on the smaller scale with the $50 \mathrm{~km}$ resolved DWD analysis, which is available only for a limited number of years (as opposed to NCEP-NCAR, which extends back to the late 1940s). Thus, we consider the DWD analysis as 'truth', that is, as a reference.

That this expectation is not groundless has already been demonstrated by Feser and von Storch (2005), who examined the performance of another limited area model in terms of air pressure and near surface temperature. They found that the regional model fares worse for air pressure than the driving NCEPNCAR analysis if spectral nudging is invoked on large-scales, but slightly better on mesoscales. This result is not surprising, as NCEP-NCAR has assimilated various local observations of the atmospheric mass distribution, which is dominated by largescale features. Thus, the limited area model, which 'knows' less about reality than NCEP-NCAR, namely conditions along the margins and about the large-scale wind above $850 \mathrm{hPa}$, cannot fare better than the global re-analysis. However, it is reassuring that in Feser's results the slight deterioration in the description of the large-scale is small enough to still harvest the added value 


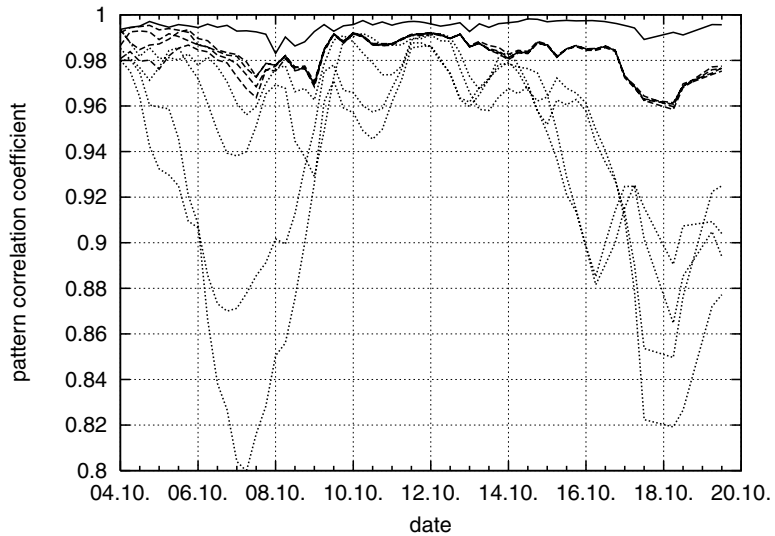

Fig. 6. Six-hourly time-series of mslp pattern correlation coefficients between DWD and NCEP-NCAR analysis data (solid) and DWD analysis data and CLM simulation data, nudged (dashed) and non-nudged (dotted) over all maritime grid cells from 4 to 20 October 1993.

on the mesoscale, which the model derives from the regional physiographic detail and the improved dynamical description associated with a fine grid resolution.

Here we examine the similarity of mean sea level pressure between our simulations and the analyses data. First, we compare the full fields, given by DWD analysis, NCEP-NCAR and the various CLM simulations. The measure used is the pattern correlation coefficient. Later we introduce a digital filter to separate the models performance on medium scales. With this tool we assess the skill of the model on these scales, where we hope for 'added value'.

Figure 6 shows the time series of pattern correlation coefficients (PCCs) between the air pressure over the ocean given by the DWD on the one hand, and on the other hand the NCEPNCAR re-analysis (after suitable interpolation; solid line), the four CLM-sn simulations (dashed lines) and the four CLM-nn simulations (dotted lines). All in all the NCEP-NCAR analysis provides a 'better' description of the marine air pressure distribution than the regional model, even if it fails to depict the polar low at 15 October (cf. Figs. 3a and b). The pattern correlation coefficients vary little within the four-member sn-ensemble, and are higher, and often much higher than the pattern correlation coefficients involving the more variable nn-members.

This also holds for time-series for PCCs between wind speed from CLM and HOAPS. The PCCs are positive most of the time indicating the similarity of the simulations with the observational data (not shown). A higher mean PCC points out the advantage of the spectrally nudged simulations to reproduce the whole fields (Table 2). The relatively high root mean squared errors between PCCs of the members of the nn-ensemble reflect their high variability, whereas values below 0.05 reflect the successful control exerted by the nudging procedure.
Table 1. Mean difference (bias) and its standard deviation between $10 \mathrm{~m}$ wind speed as provided by CLM01-sn, CLM01-nn and CLM02-nn and HOAPS between 0 and 12 UTC 15 October (cf. Fig. 5)

\begin{tabular}{cccc}
\hline & CLM01-sn & CLM01-nn & CLM02-nn \\
\hline HOAPS & $-1.92 \pm 3.27$ & $0.02 \pm 4.02$ & $-0.44 \pm 3.51$ \\
\hline
\end{tabular}

The separation of the mesoscale circulation from the largescale is achieved by using a near-isotropic two-dimensional digital filter (Feser and von Storch, 2005). We constructed such a digital filter, with a footprint of $21 \times 21$ grid points and the twodimensional wave number $k^{*}$, which approximates the response function $\kappa\left(k^{*}\right)=0$ for all $k^{*} \leq 6, \kappa\left(k^{*}\right)=1$ for all $k^{*} \in[8,15]$, and $\kappa\left(k^{*}\right)=0$ for all $k^{*} \geq 18$. That is, phenomena on scales larger than approximately $\frac{3516}{6} \mathrm{~km} \approx 600 \mathrm{~km}$ and smaller than approximately $\frac{3516}{18} \mathrm{~km} \approx 200 \mathrm{~km}$ are filtered out, while scales between 230 and $450 \mathrm{~km}$ are to first order retained. Using such a filter, we want to make the polar low more distinct compared to the untreated output fields.

When the bandpass filter is applied to the NCEP-NCAR air pressure and wind speed field of 15 October 1993 (Fig. 7a), rather smooth fields are obtained, apart from some orographic features, which may originate from the spatial interpolation to the $50 \mathrm{~km}$ CLM grid. No indication of the polar low is present. In the filtered DWD data (Fig. 7b) a mesoscale disturbance can be seen for surface pressure and for wind speed at the polar low's location in accordance with Fig. 3a. (Areas without values in the north of Fig. $7 \mathrm{~b}$ are due to the limited spatial extension of the DWD-grid.)

Figures $8 \mathrm{a}-\mathrm{h}$ display the bandpass filtered air pressure and $10 \mathrm{~m}$ wind speed in the four members of the sn-ensemble and in the four members of the nn-ensemble. Minor anomalies in sea level pressure, probably caused by orographic effects, exist over mountainous land areas in Greenland, Iceland and at the Norwegian Coast (not shown). The only significant maritime disturbance in air pressure is located near the polar low's position (given by black points) in the respective untreated fields. This fact could be used for an automatic polar low detection, that is, locating the filtered maritime pressure minimum would return the polar low's position in this case. Additionally the largest wind speed anomalies are found in this area. As before, the bandpass filtered maps for the four large-scale constrained simulations (sn) are rather similar to each other. Equally consistent with Fig. 3 is the finding that in two of the nn-simulations, CLM02-nn and CLM03-nn, a mesoscale disturbance can be identified, whereas in the other two simulations differently shaped mesoscale features are found. In CLM02-nn and CLM03-nn the mesoscale anomalies seem to be more pronounced than those in the nudged simulations. 
Table 2. For the period 4-20 October 1993 pattern correlation coefficients (PCC) were calculated between wind speeds from HOAPS and the respective simulations with CLM. Here the resulting mean PCCs and root mean squared errors between the respective nudged (a) and non-nudged (b) time series are shown

\begin{tabular}{cccccc}
\hline & Mean PCC & CLM01-sn & CLM02-sn & CLM03-sn & CLM04-sn \\
\hline (a) CLM-sn & & & & & \\
CLM01-sn & 0.642 & & 0.036 & 0.039 & 0.048 \\
CLM02-sn & 0.651 & 0.036 & & 0.034 & 0.035 \\
CLM03-sn & 0.649 & 0.039 & 0.034 & & 0.037 \\
CLM04-sn & 0.654 & 0.048 & 0.035 & 0.037 & \\
& Mean PCC & CLM01-nn & CLM02-nn & CLM03-nn & CLM04-nn \\
(b) CLM-nn & & & & & \\
CLM01-nn & 0.510 & & 0.235 & 0.283 & 0.147 \\
CLM02-nn & 0.471 & 0.235 & & 0.170 & 0.233 \\
CLM03-nn & 0.417 & 0.283 & 0.170 & & 0.311 \\
CLM04-nn & 0.571 & 0.147 & 0.233 & 0.311 & \\
\hline
\end{tabular}
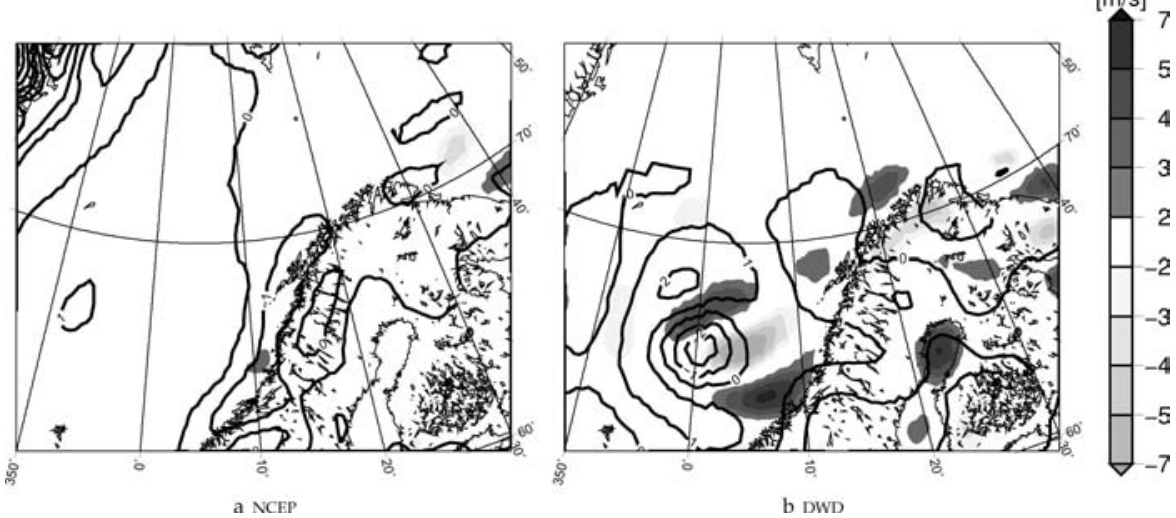

Fig. 7. Bandpass filtered mean sea level air pressure $(\mathrm{hPa})$ and $10 \mathrm{~m}$ wind speed from NCEP-NCAR analysis data and from DWD analysis data at 0600 UTC 15 October 1993.

\subsection{Results for two further cases}

In this subsection, we demonstrate that similar findings also hold for the two other investigated polar lows, namely cases that occurred in December 1993 and in January 1998. The first case developed on 8 December 1993 southwest of Iceland in connection with a $500 \mathrm{hPa}$ upper level cold core vortex southwest of Iceland and took an eastward track (Rasmussen and Turner, 2003). The second case developed on 18 January 1998 between Iceland and Norway in a vast cold air outbreak and was manifested as a low-level convergence/upper-level divergence system associated with the upper-level jet stream core (Rasmussen and Turner, 2003 referring to Nielsen, 1998). Weather charts in (Figs. 9a and b) display the observed positions of both polar lows in their mature stages. Ensemble simulations with CLM, nudged and non-nudged, were initiated at 0000 UTC on 22-25 November 1993 and on 1-4 January 1998, respectively.

Examples for the respective simulations making use of spectral nudging are shown in (Figs. 9a and d). The respective other ensemble members are virtually identical. Similarities between the wind fields simulated in the four spectrally nudged simulations and HOAPS are again described by positive pattern correlation coefficients (not shown). Again these coefficients are higher and less variable within the ensemble in the case of the spectrally nudged simulations compared to the unconstrained ones. Like before, resemblances of large-scale mslp-patterns between the simulated data and the weather charts can be seen. Also the polar lows with closed pressure minima, though very small in Fig. 9c, and wind speeds near and above gale force are simulated. Value and location of the simulated polar lows' pressure minima are closer to the observations in comparison with the 'Le Cygne'-case in October 1993.

Again the deepening of the mesoscale disturbance becomes more discernible after applying the digital bandpass filter (Fig. 10a). In all the ensemble members of the nudged simulations of the 1993 case an anomaly, though small, representing the polar low can be seen. For the sake of brevity, we do without showing the filtered fields of the virtually identical other 


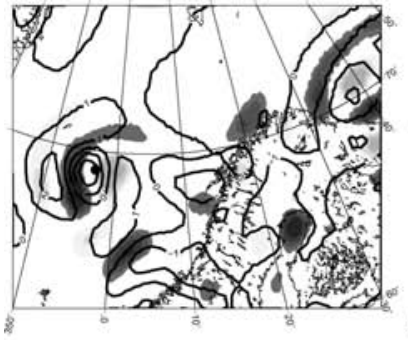

a CLM01-sn

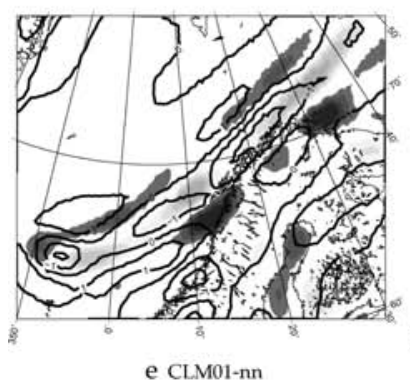

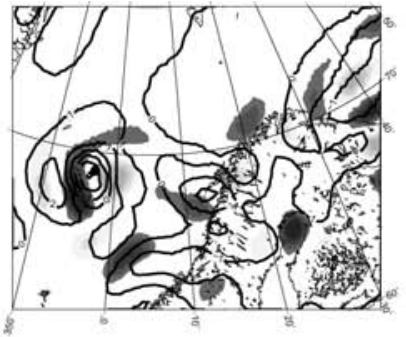

b CLM02-sn

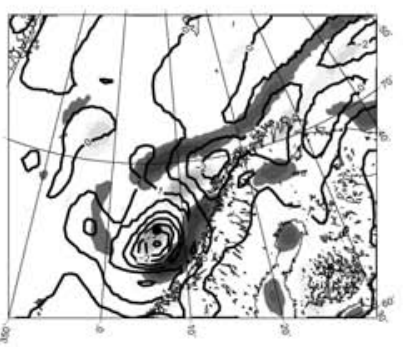

f CLM02-nn

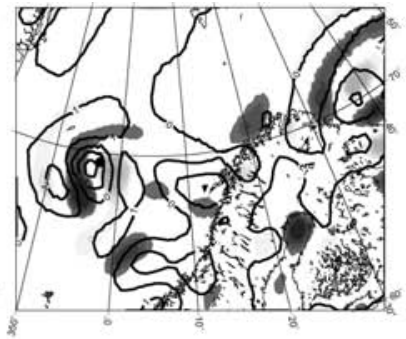

c CLM03-sn

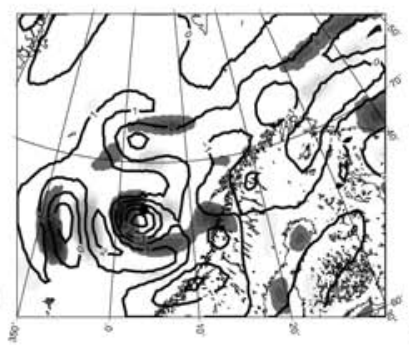

g CLM03-nn

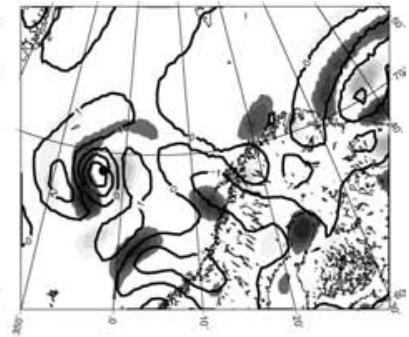

d ClM04-sn

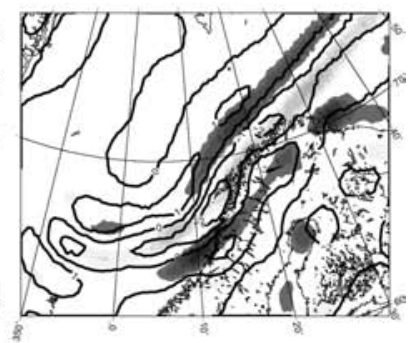

h CLM04-nn

Fig. 8. Bandpass filtered mslp (isolines; hPa) and $10 \mathrm{~m}$ wind speed anomalies (see scale in Fig. 7) from CLM ensemble runs with spectral nudging (a-d) and without (e-h) at 0900 UTC 15 October 1993. If existent, black dots indicate the positions of the polar low's pressure minimum in the respective untreated field of the ensemble run.
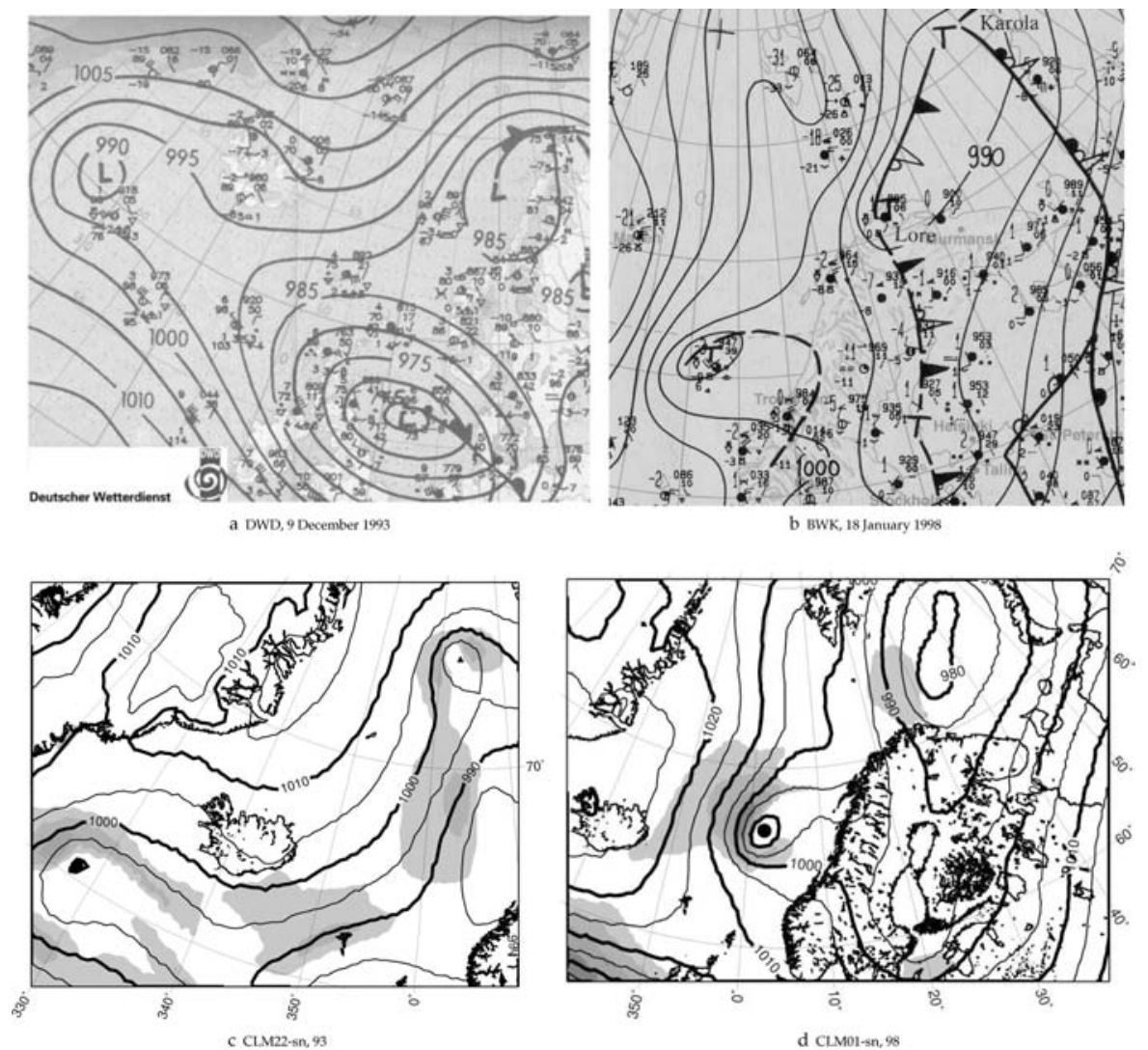

Fig. 9. Surface weather chart from the German Weather Service (a) at 0000 UTC 9 December 1993, and from the Free University of Berlin (b) at 0100 UTC 18 January 1998. Full CLM mslp (isolines; hPa) and $10 \mathrm{~m}$ wind speed (same scale as in Fig. 3) at 0000 UTC 9 December 1993 (c) and at 0000 UTC 18 January 1998 (d). The dot marks the position of the polar low in the lower two diagrams. 

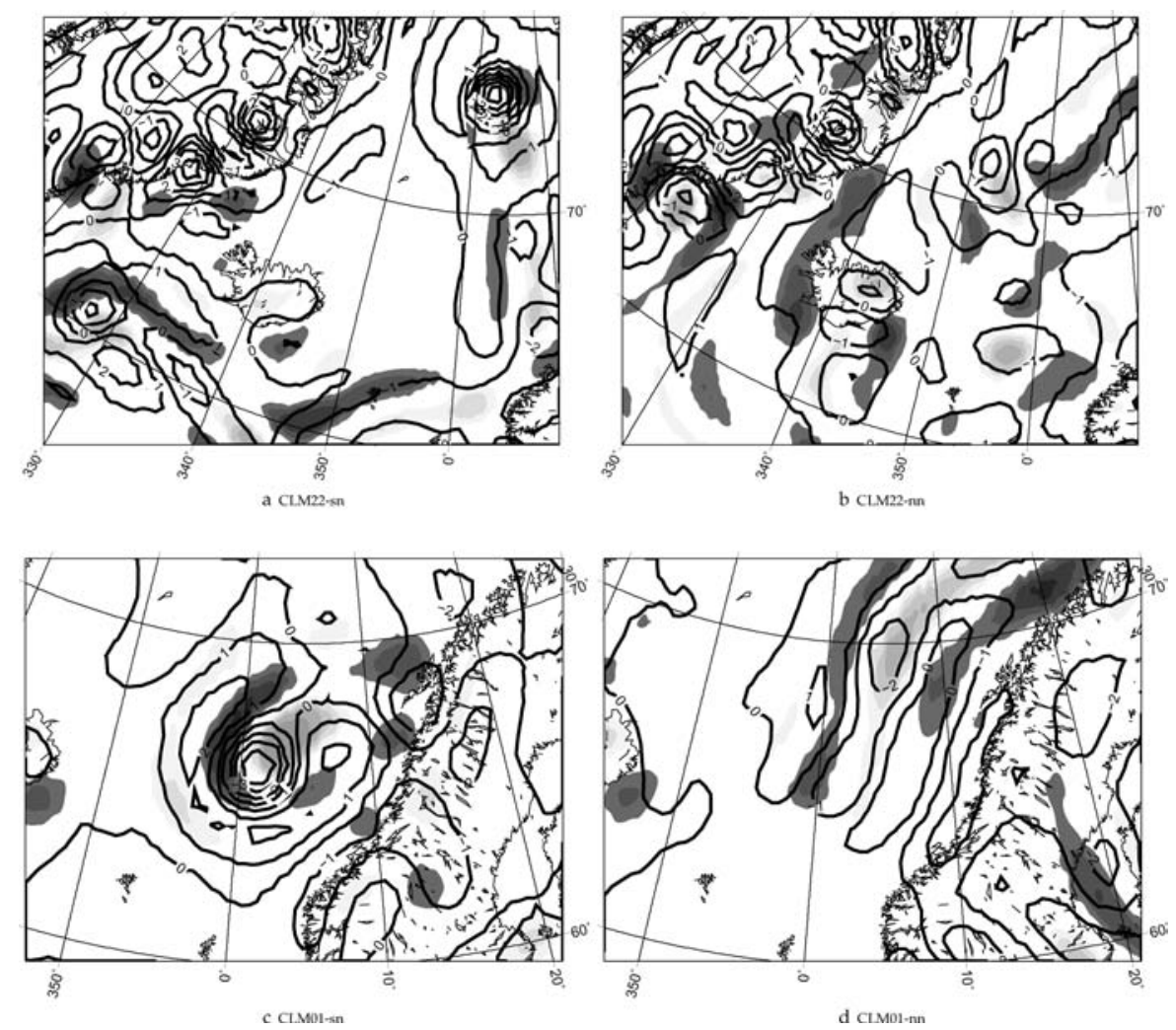

Fig. 10. Bandpass filtered mslp (isolines; hPa) and $10 \mathrm{~m}$ wind speed anomalies (see scale in Fig. 7) from CLM ensemble runs with spectral nudging $(\mathrm{a}+\mathrm{c})$ and without $(\mathrm{b}+\mathrm{d})$ at 0000 UTC 09 December1993 $(\mathrm{a}+\mathrm{b})$ and 000 UTC 18 January $1998(\mathrm{c}+\mathrm{d})$.

ensemble members. Interestingly an additional mesoscale disturbance south of Spitsbergen appears in the simulation results at about $77^{\circ} \mathrm{N}, 5^{\circ} \mathrm{E}$. Presumably this mesoscale disturbance was induced because favourable large-scale conditions, such as a northerly wind component, prevailed in this area. Here we cannot decide whether this is a model artefact or whether there is a deficiency in the weather chart, which is based on very few observational data in that region. The feature is, however, present in all members of the ensemble of four simulations. A low pressure bulge in the DWD data and HOAPS wind speeds near gale force at 0600 UTC 9 December 1993 (not shown), support the assumption that the feature may be real. In the non-nudged ensemble members the polar low develops in none of the realizations. This points out the importance of the large-scale forcing which is successfully exerted by the nudging procedure.

The polar low in January 1998 is also reproduced (Fig. 10c). A notably strong anomaly in the filtered fields develops in all of the nudged ensemble members. If spectral nudging is left out, these anomalies do not show up in any of the realizations. An example filtered field is shown in (Fig. 10d).

Above we argued that 'Le Cygne's' misplacement in space, time and value of the pressure minimum might be linked to the role that processes in the lower part of the atmosphere play in its development (see Section 3.1). These levels are beyond the direct influence of the spectral nudging, which only affects levels above $850 \mathrm{hPa}$. Contrary the development of these two polar lows was dominated by processes in the upper levels. Such upper level forcing can directly enter the simulations via the spectral nudging method and thus, by interacting with the lower parts of the atmosphere, determine the polar low development more 'correctly'. When no upper level large-scale information is allowed in the model's interior, these two polar lows do not develop, not even occasionally.

\section{Discussion}

We have analysed whether a LAM/RCM is able to properly describe features of polar lows when run in climate mode. Contrary to usual numerical case studies, which commonly investigate the different dynamical processes involved in polar low development and use initial fields nearby in time, our simulations were induced approximately 2 weeks prior to the respective polar low formation. We run our model in conventional mode only with lateral boundary conditions as well as additionally constrained to maintain the 'correct' large-scale circulation. This is obtained by using the spectral nudging methodology of von Storch et al. (2000). We find that the technique is indeed successful, and much nearer to observations than a simulation without such a constraint. 
In the three cases considered and with the spectral nudging procedure invoked, polar low development principally takes place at about the right time and at about the right location. However for one polar low there are larger differences in detail between model and observations. For instance, the core pressure of the polar low in the simulation deviates from what observational evidence points to. Also the location of the minimum pressure deviates by a distance of several $100 \mathrm{~km}$ in one case. It seems that in conventional mode polar lows are only reproduced occasionally.

We found signs that the spectral nudging procedure is particularly successful for polar lows, which basically originate from upper level disturbances. This is plausible because via the spectral nudging a large-scale closer to observations is enforced onto the simulations. As a result more realistic and less random upper level fields are generated. Assuming a proper description of interactions between upper and lower levels in CLM, these more realistic upper level fields in turn determine a more realistic polar low development. Accordingly without spectral nudging, these polar lows did not develop at all. However, based on our few cases studies, we cannot offer a statistically supported hypothesis.

In another study on the performance of spectrally nudged, multidecadal simulations, similar features were found. Events were simulated qualitatively correct, but deviations in detail showed up. In this study more cases were available, so that the statistics and not only the cases could be evaluated - and it turned out that the deviations were not systematic and the statistics of the events were indeed well reproduced (Feser, 2006). We suggest that a similar situation may hold here. Of course at this time such a statement is a hypothesis, which needs to be tested in a larger ensemble of cases.

We applied a spatial digital bandpass filter to the simulated output fields. In this way, the reproduced polar lows became more distinct. We think that such a filter can be utilised in forthcoming investigations on climatological aspects of polar low occurrences in the North Atlantic. Such questions have been addressed by Kolstad (2006) or Condron et al. (2006) before. However they were not able to single out individual polar low occurrences. The minima in the bandpass filtered fields of a multidecadal simulation might serve as a base for a detection algorithm. Of course further constraints have to be applied. For instance, a wind speed criterion should be implied. Also disturbances due to orography have to be excluded. The definite constraints of such a detection algorithm will have to be subject of further investigations. Then it might be possible to detect single polar low occurrences in the output fields of multidecadal simulations run with spectral nudging invoked. Such a detection might serve as a base to investigate further climatological aspects of polar lows.

In a preliminary study we examined how another model, namely REMO (Zahn and von Storch, 2006) using a less suitable region (Feser et al., 2001), was dealing with the formation of polar lows. These results are consistent with what we have reported above. Therefore, we suggest that our results do not depend on the specific model CLM used in this study We conclude that important statistics of polar lows, such as frequency of formation and tracks, may be described homogeneously by our method over several decades; thus assessments of recent, ongoing and possibly even future trends appear possible.

\section{Acknowledgment}

We are thankful to B. Rockel and B. Geyer for their help with the model, to F. Feser for her help with the digital filter and to A. Andersson for providing the HOAPS-data. We are also thankful to J. Winterfeldt and Tom Bracegirdle for reading the manuscript. The work was conducted within the Virtual Institute (VI) EXTROP which is promoted by the 'Initiative and Networking Fund' of the Helmholtz Association.

\section{References}

Andersson, A., Bakan, S., Fennig, K., Grassl, H., Klepp, C.-P. and coauthors. 2007. Hamburg ocean atmosphere parameters and fluxes from satellite data-hoaps-3-twice daily composite. Electronic publication: doi:10.1594/WDCC/HOAPS3_DAILY.

Blier, W. 1996. A numerical modeling investigation of a case of polar airstream cyclogenesis over the Gulf of Alaska. Mon. Wea. Rev. 124, 2703-2725.

Böhm, U., Kücken, M., Ahrens, W., Block, A., Hauffe, D. and co-authors. 2006. CLM - the climate version of LM: brief description and longterm applications. COSMO Newslett. 6, 225-235.

Böhm, U., Kücken, M., Hauffe, D., Gerstengarbe, F.-W., Werner, P., Flechsig and co-authors. 2004. Reliability of regional climate model simulations of extremes and of long-term climate. Nat. Hazards Earth Syst. Sci. 4, 417-431.

Bracegirdle, T. J. and Gray, S. L. 2006. The Role of Convection in the Intensification of Polar Lows. PhD Thesis. The University of Reading, UK, 69 pp.

Bracegirdle, T. J. and Gray, S. L. 2008. An objective climatology of the dynamical forcing of polar lows in the Nordic seas. Int. J. Climatol. doi:10.1002/joc. 1686.

Bresch, J. F., Reed, R. J. and Albright, M. D. 1997. A polar-low development over the Bering Sea: analysis, numerical simulation, and sensitivity experiments. Mon. Wea. Rev. 125, 3109-3130.

Carleton, A. M. and Carpenter, D. A. 1990. Satellite climatology of "polar lows" and broadscale climatic associations for the Southern Hemisphere. Int. J. Climatol. 10, 219-246.

Claud, C., Heinemann, G., Raustein. E. and Mcmurdie, L. 2004. Polar low 'Le Cygne': satellite observations and numerical simulations. Quart. J. Roy. Meteor. Soc. 130, 1075-1102.

Condron, A., Bigg, G. R. and Renfrew, I. A. 2006. Polar Mesoscale Cyclones in the Northeast Atlantic: comparing Climatologies from ERA-40 and Satellite Imagery. Mon. Wea. Rev. 134, 1518-1533, doi:10.1175/MWR3136.1.

Davies, H. C. 1976. A lateral boundary formulation for multi-level prediction models. Quart. J. Roy. Meteorol. Soc. 102, 405-418.

Déqué, M., Jones, R., Wold, M., Giorgi, F., Christensen, J. and co-authors. 2005. Global high resolution versus limited area 
model climate change projections over Europe: quantifying confidence level from PRUDENCE results. Climate Dyn. 25, 653-670, doi:10.1007/s00382-005-0052-1.

Emanuel, K. A. 1986. An air-sea interaction theory for tropical cyclones. Part I: steady-state maintenance. J. Atmos. Sci. 43, 585-605.

Emanuel, K. A. and Rotunno, R. 1989. Polar lows as arctic hurricanes. Tellus 41A, 1-17.

Feser, F. 2006. Enhanced detectability of added value in limited area model results separated into different spatial scales. Mon. Wea. Rev. 134, 2180-2190.

Feser, F. and von Storch, H. 2005. A spatial two-dimensional discrete filter for limited area model evaluation purposes. Mon. Wea. Rev. 133, 1774-1786.

Feser, F., Weisse, R. and von Storch, H. 2001. Multi-decadal atmospheric modeling for Europe yields multi-purpose data. EOS Trans. 82 , pp. 305, 310.

Grønås, S. and Kvamstø, N. 1995. Numerical simulations of the synoptic conditions and development of arctic outbreak polar lows. Tellus $\mathbf{4 7 A}$, 797-814.

Harold, J. M., Bigg, G. R. and Turner, J. 1999a. Mesocyclone activities over the north-east Atlantic. Part 1: vortex distribution and variability. Int. J. Climatol. 19, 1187-1204.

Harold, J. M., Bigg, G. R. and Turner, J. 1999b. Mesocyclone activities over the north-east Atlantic. Part 2: an investigation of causal mechanisms. Int. J. Climatol. 19, 1283-1299.

Harrold, T. W. and Browning, K. A. 1969. The polar low as a baroclinic disturbance. Quart. J. Roy. Meteorol. Soc. 95, 710-723.

Heinemann, G. 1998. A meso-scale model-based study of the dynamics of a wintertime polar low in the Weddell Sea region of the Antarctic during WWSP86. J. Geophys. Res. 103, 5983-6000.

Heinemann, G. and Klein, T. 2003. Simulations of topographically forced mesocyclones in the Weddell Sea and the Ross Sea region of Antarctica. Mon. Wea. Rev. 131, 302-316.

Kalnay, E., Kanamitsu, M., Kistler, R., Collins, W., Deaven, D. and coauthors. 1996. The NCEP/NCAR reanalysis project. Bull. Am. Meteorol. Soc. 77, 437-471.

Kolstad, E. 2006. A new climatology of favourable conditions for reverse-shear polar lows. Tellus 58A, 344-354, doi:10.1111/j.1600 0870.2006.00171.x.

Lee, T.-Y., Park, Y.-Y. and Lin, Y.-L. 1998. A numerical modeling study of mesoscale cyclogenesis to the east of the Korean Peninsula. Mon. Wea. Rev. 126, 2305-2329.
Mailhot, J., Hanley, D., Bilodeau, B. and Hertzman, O. 1996. A numerical case study of a polar low in the Labrador Sea. Tellus $\mathbf{4 8 A}$, 383-402.

Nielsen, N. W. 1997. An early Autumn polar low formation over the Norwegian Sea. J. Geophys. Res. 102, 13955-13973.

Nielsen, N. W. 1998. Om forudsigelighed af polare lavtryk (on the predictability of polar lows). Vejret 20, 37-48. (In Danish).

Nordeng, T. and Rasmussen, E. 1991. A most beautiful polar low. A case study of a polar low development in the Bear Island region. Tellus $44 \mathrm{~A}$, 81-99.

Rasmussen, E. 1979. The polar low as an extratropical CISK disturbance. Quart. J. Roy. Meteor. Soc. 105, 531-549.

Rasmussen, E. 1985. A case study of a polar low development over the Barents Sea. Tellus 37A, 407-418.

Rasmussen, E. and Turner, J. 2003. Polar Lows: Mesoscale Weather Systems in the Polar Regions. Cambridge University Press, Cambridge.

Steppeler, J., Doms, G., Schättler, U., Bitzer, H., Gassmann, A. and coauthors. 2003. Meso-gamma scale forecasts using the nonhydrostatic model LM. Meteorol. Atmos. Phys. 82, 75-96.

von Storch, H., Langenberg, H. and Feser, F. 2000. A spectral nudging technique for dynamical downscaling purposes. Mon. Wea. Rev. 128, 3664-3673.

Weisse, R., von Storch, H. and Feser, F. 2005. Northeast Atlantic and North Sea storminess as simulated by a regional climate model 19582001 and comparison with observations. J. Climate 18, 465-479, doi:10.1175/JCLI-3281.1.

Wilhelmsen, K. 1985. Climatological study of gale-producing polar lows near Norway. Tellus 37A, 451-459.

Woth, K., Weisse, R. and von Storch, H. 2006. Climate change and north sea storm surge extremes: an ensemble study of storm surge extremes expected in a changed climate projected by four different regional climate models. Ocean Dyn. 56, 3-15, doi:10.1007/s10236005-0024-3.

Yanase, W., Fu, G., Niino, H. and Kato, T. 2004. A polar low over the Japan Sea on 21 january 1997. Part II: a numerical study. Mon. Wea. Rev. 132, 1552-1574.

Yanase, W., Niino, H. and Saito, K. 2002. High-resolution numerical simulation of a polar low. Geophys. Res. Lett. 29, 1658.

Zahn, M. and von Storch, H. 2006. Simulation of a Polar Low Case in the North Atlantic with Different Regional Numerical Models. WGNE report “Blue Book 2006”, 2pp. 